\title{
Radiographic signs associated with inferior alveolar nerve damage following lower third molar extraction
}

\author{
Cristina Palma-Carrióo ${ }^{1}$, Berta García-Mira ${ }^{2}$, Carolina Larrazabal-Morón ${ }^{3}$, María Peñarrocha-Diago ${ }^{2}$
}

\author{
${ }^{1}$ Student of Master of Oral Surgery and Implantology, Valencia University Medical and Dental School, Valencia, Spain \\ ${ }^{2}$ Professor Assistant of Oral Surgery. Master of Oral Surgery and Implantology, Valencia University Medical and Dental \\ School, Valencia, Spain \\ ${ }^{3}$ Master of Oral Surgery and Implantology, Valencia University Medical and Dental School, Valencia, Spain
}

\author{
Correspondence: \\ Clínicas Odontológicas \\ Gascó Oliag, 1 \\ 46021-Valencia (Spain) \\ berta.garcia@uv.es
}

Received: 18/05/2009

Accepted: 06/03/2010

\begin{abstract}
Palma-Carrió C, García-Mira B, Larrazabal-Morón C, Peñarrocha-Diago MA. Radiographic signs associated with inferior alveolar nerve damage following lower third molar extraction. Med Oral Patol Oral Cir Bucal. 2010 Nov 1;15 (6):e886-90.
\end{abstract}

http://www.medicinaoral.com/medoralfree01/v15i6/medoralv15i6p886.pdf

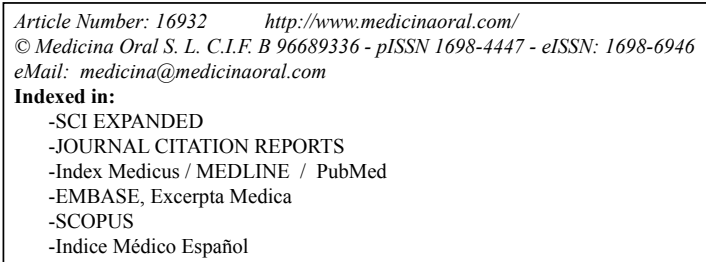

\begin{abstract}
The aim was to carry out a literature review of preoperative radiographic signs in orthopantomography (OPG) and computed tomography (CT) related with the risk of inferior alveolar nerve damage during the surgical extraction of lower third molar (LTM). A search was made on PubMed for literature published between the years 2000 and 2009.

In the reviewed literature, radiographic signs in the OPG that indicate a relationship between the LTM and the inferior alveolar canal are considered a risk factor for nerve damage. These signs are darkening and deflection of the root, and diversion and interruption in the white line of the canal. In the majority of these studies, the routine use of CT is not justified, and is only recommended when radiographic signs appear in the OPG that demonstrate a direct anatomical relationship between the LTM and the canal. In the CT, the absence of cortical bone in the canal implies a contact between the root of the LTM and the canal, and is related with the presence of some radiographic signs in the OPG. Some studies demonstrate that despite the absence of cortical bone, the risk of lesion or exposure of the nerve during the extraction of LTM was low.
\end{abstract}

Key words: Third molar, inferior alveolar nerve, orthopantomography, computed tomography.

\section{Introduction}

The surgical extraction of a lower third molar is a frequent treatment carried out for orthodontic or prophylactic reasons (1). The proximity of the lower third molar (LTM) to the inferior alveolar canal in the preoperative radiographic study is considered a risk factor for damage to the inferior alveolar nerve (2-5), the incidence of which is approximately $1.1 \%$ (6). This is an infrequent lesion, but can have serious complications for the patient and therefore the correct diagnosis is important (7).
Orthopantomography (OPG) is the diagnostic method of choice to evaluate the surgical extraction of the LTM (7). In 1999, Rood and Shehab (2), in a literature review, collected seven radiographic indicators of a close relationship between the LTM and the inferior alveolar canal. Four signs were observed in the tooth root (darkening, deflection and narrowing of the root, and a bifid root apex), and the other three in the canal (diversion, narrowing, and interruption in the white line of the canal) (Fig. 1). The authors collected retrospective data 

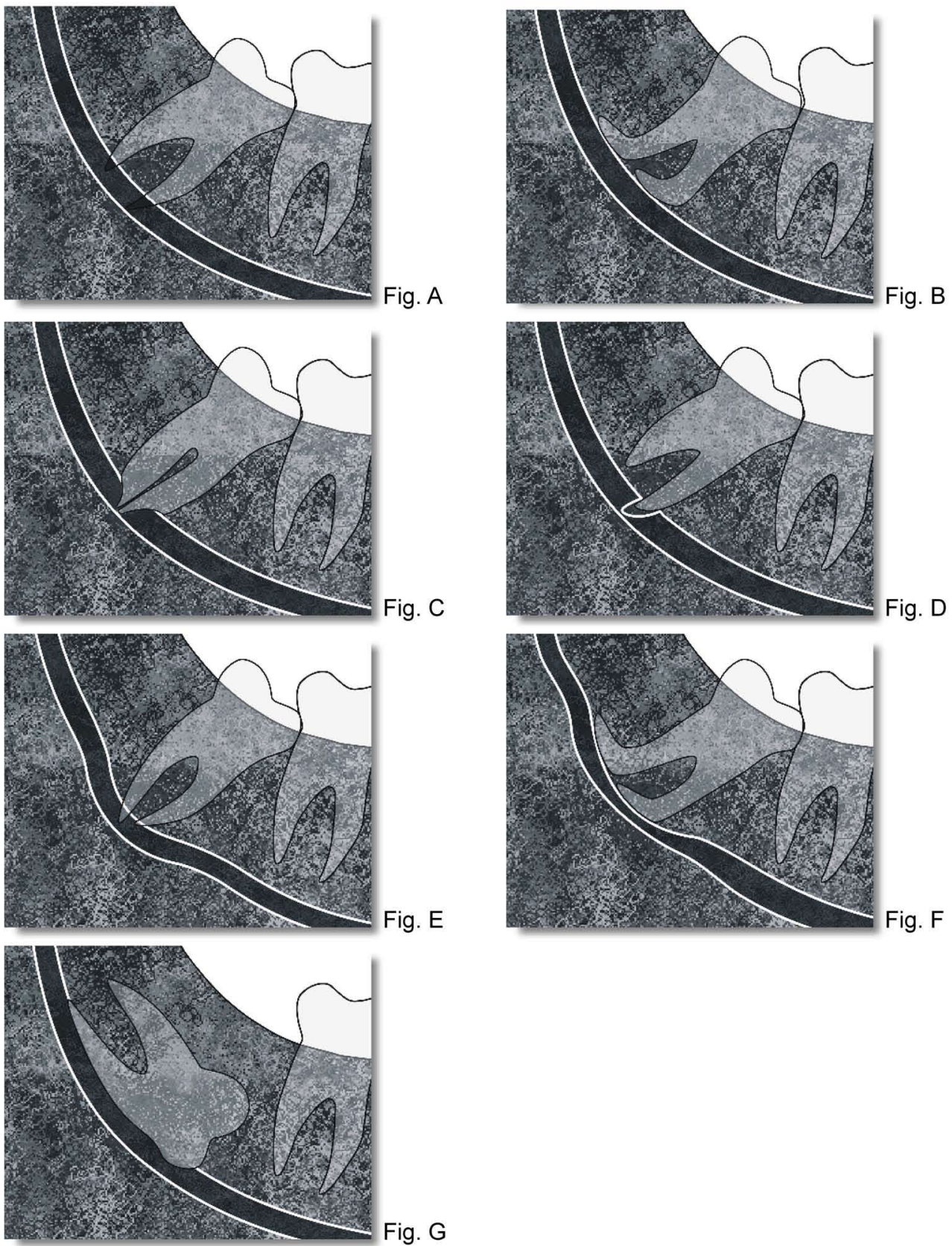

Fig. 1.

A - Darkening of root; B - Deflection of root; C - Narrowing of root; D - Bifid root apex; E - Diversion of canal; $\mathrm{F}$ - Narrowing of canal; $\mathrm{G}$ - Interruption in white line of canal. 
on 553 patients and prospective data on 552, observing the appearance of some of the radiographic indicators of a close relationship between the LTM and the inferior alveolar canal in the OPG in $9.1 \%$ and $16.4 \%$ of cases respectively. In the retrospective study, nerve damage was statistically related with all the radiographic signs except bifid root apex and darkening of the canal. In the prospective study, nerve damage was related with diversion of the canal, followed by darkening of the root and interruption of the canal.

For some authors $(5,8)$, computed tomography (CT) is a better technique for evaluating the anatomical structures and provides greater intraoperative safety; however, the routine use of CT in the extraction of impacted LTM is not recommended (7-13) due to the high radiation dose and cost (13). Susarla and Dodson (10), preoperatively evaluated 46 LTM, 80.4\% were classified as high risk in the OPG, and $32.6 \%$ in the CT; the authors concluded that CT provides sufficient information to change the OPG classification from high to low risk of nerve damage. The majority of studies $(4,5,7-9,12)$ recommend CT when radiographic signs (diversion, narrowing and interruption in the white line of the canal, and darkening of the root) appear in the OPG, indicating a direct relationship between the LTM and the inferior alveolar canal.

The aim of this study was to review the literature on radiographic signs in OPG and $\mathrm{CT}$ related with risk of damage to the inferior alveolar nerve during surgical extraction of an impacted LTM.

\section{Search methodology}

A search was made of PubMed for articles published between 2000 and 2009 that evaluated the relationship between the LTM and the inferior alveolar canal by OPG and CT using the radiographic signs described by Rood and Shehab (2). The keywords used were 'third molar', 'inferior alveolar nerve', 'panoramic radiography' and 'X-ray computed tomography'. Studies with a minimum of 20 patients for which the full text was obtained were included. Four studies were excluded for having less than 20 patients, six for not having the full text available and nine for not including the radiographic signs of Rood and Shehab (2). In total 12 studies were included (3-5,7-16).

\section{Orthopantomography}

Table 1 shows the four studies that evaluated radiographic signs associated with nerve damage $(3,7,13,14)$. It can be seen that diversion of the canal was the radiographic sign associated with nerve damage in the majority of the published studies. Narrowing of the root was the least associated sign. For Valmaseda-Castellón et al. (3), diversion of the canal was the only radiographic sign statistically associated with nerve damage. For Blaeser et al. (7), darkening of the root, interruption in the white

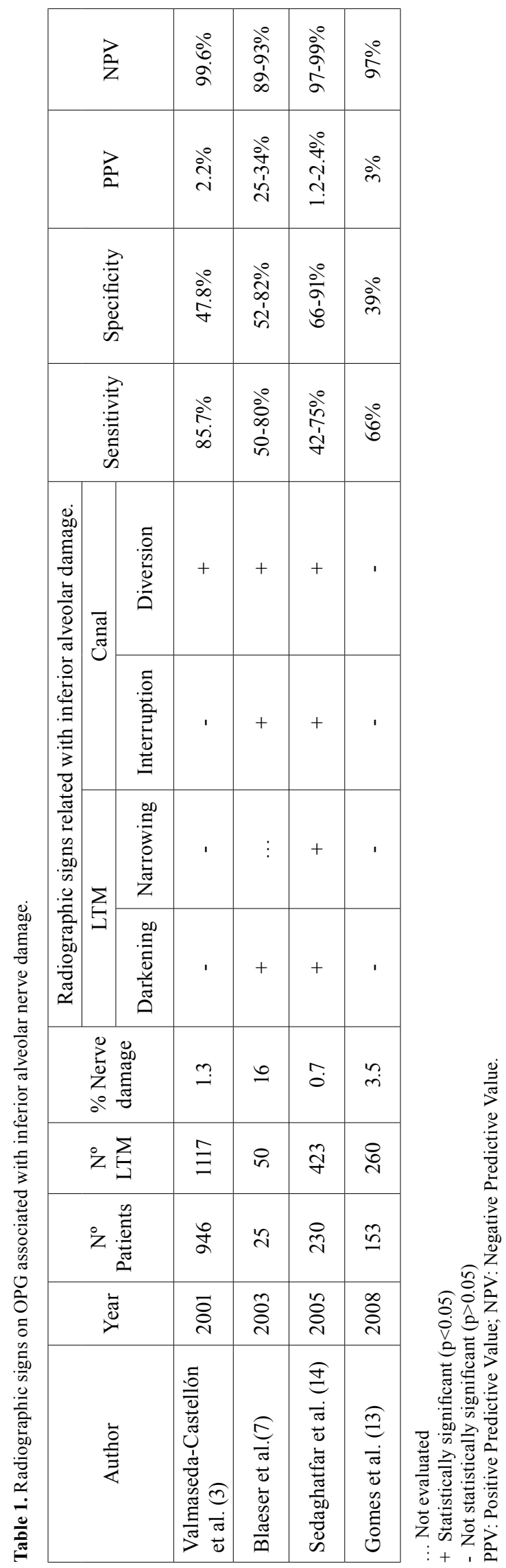


line of the canal and the diversion of the canal were all statistically related with nerve damage. Sedaghatfar et al. (14) observed four radiographic signs (darkening and narrowing of the root, and interruption in the white line and diversion of the canal) statistically associated with nerve exposure during LTM extraction, and therefore carrying an increased risk of nerve damage. However, Gomes et al. (13) did not observe any statistically significant relationship with any radiographic sign; for these authors, the OPG does not provide any definitive data to predict nerve damage during surgery of LTM.

With respect to the sensitivity of OPG, this varies between 42 and $85.7 \%$ in the published studies (Table 1) $(3,7,13,14)$. For Gomes et al. $(13)$, there was some associated radiographic sign in $66 \%$ of cases with nerve damage; having a low sensitivity, since changes to the inferior alveolar nerve were found even in cases with lack of contact with the mandibular canal (33\%).

The published studies describe the probability of nerve damage in the presence of associated radiographic signs, also known as positive predictive value (PPV). The PPV values varied between $2.2 \%$ and $3 \%$ in the majority of studies $(3,13,14)$; these figures indicate a low risk of nerve damage in the presence of radiographic indications of a relationship between the LTM and the canal. The negative predictive value (NPV) is the probability of not damaging the nerve when these radiographic signs are absent; and vary between 97 and $99 \%(3,13$, 14). These figures indicate a minimum risk of nerve damage in the absence of radiographic signs. However, in the study by Blaeser et al. (7) the PPV was higher and the NPV lower, since the criteria used ( 8 cases with nerve damage and 17 controls) produced an artificially high prevalence of nerve damage $(16 \%)$.

\section{Orthopantomography and computed tomography}

Studies have been published $(4,5,8,9,11,12,16)$ that evaluate the relationship between the LTM and the canal both on the OPG and in the CT. In the CT, the absence of cortical bone of the alveolar canal implies contact with the root of the LTM (11) and has been related with radiographic signs in the OPG, such as narrowing, diversion and interruption in the white line of the canal and darkening of the root (Table 2) $(4,5,11,12)$. Nakagawa et al. (11) observed that interruption in the white line of the canal in the OPG was related with the absence of cortical bone in the CT; obtaining a sensitivity of 0.64 (of 56 cases with absence of cortical bone, interruption in the white line of the canal was observed in 36), and a specificity of 0.65 , (of the 17 cases with cortical present in the CT, interruption in the white line of the canal was not observed in the OPG in 11). The PPV (the probability that cortical bone is absent when the white line of the cortical is interrupted on the canal) was 0.86 , and the NPV was 0.35 . These results indicate that interruption in the white line of the canal in the OPG was related with absence of cortical bone in the CT.

Exposure of the nerve during extraction of the LTM has been related with an increased risk of nerve damage. The absence of cortical bone in the $\mathrm{CT}$ is a radiographic sign that predisposes this exposure $(5,12,15)$. Tantanapornkul et al. (15) when operating on 142 LTM, had 27 cases of nerve exposure. In the OPG, interruption in the white line of the canal was the radiographic sign that best predicted nerve exposure. Absence of cortical bone was shown in the CT in 25 of the 27 cases of nerve exposure. On comparing the sensitivity and specificity of the CT against OPG, figures of $93 \%$ and $77 \%$ were obtained for the $\mathrm{CT}$, and $70 \%$ and $63 \%$ for the OPG, respectively, indicating that $\mathrm{CT}$ was significantly better than OPG in predicting nerve exposure during extraction of LTM.

\section{Conclusions}

OPG is a good method for preoperative evaluation of surgical LTM extraction. The absence of radiographic signs associated with a relationship between the LTM and the canal indicates a minimum risk of nerve damage. On the other hand, exposure or damage to the nerve following

Table 2. Relationship between LTM and alveolar canal on OPG and CT.

\begin{tabular}{|c|c|c|c|c|c|c|c|c|}
\hline \multirow{3}{*}{ Author } & \multirow{3}{*}{ Year } & \multirow{3}{*}{$\begin{array}{c}\mathrm{N}^{\mathrm{o}} \\
\text { Patients }\end{array}$} & \multirow{3}{*}{$\begin{array}{c}\mathrm{N}^{\mathrm{o}} \\
\text { LTM }\end{array}$} & \multirow{3}{*}{$\begin{array}{c}\text { CT: } \mathrm{N}^{\mathrm{o}} \text { of cases with } \\
\text { absense of cortical } \\
\text { in IAC }\end{array}$} & \multicolumn{4}{|c|}{$\begin{array}{c}\text { Radiographic signs on OPG related with absence } \\
\text { of IAC cortical bone on CT }\end{array}$} \\
\hline & & & & & \multicolumn{3}{|c|}{ Canal } & LTM root \\
\hline & & & & & $\begin{array}{l}\text { Interrup- } \\
\text { tion }\end{array}$ & Diversion & Narrowing & Darkening \\
\hline Monaco et al. (4) & 2004 & 44 & 73 & 50 & + & - & + & + \\
\hline Nakawaga et al. (11) & 2007 & 65 & 73 & 56 & + & $\ldots$ & $\ldots$ & $\ldots$ \\
\hline Nakamori et al. (12) & 2008 & 443 & 119 & 48 & - & + & + & + \\
\hline Jhamb et al. (5) & 2009 & 29 & 31 & 9 & + & - & + & + \\
\hline
\end{tabular}

IAC: Inferior alveolar canal

... Not evaluated

+ Statistically significant $(\mathrm{p}<0.05)$

- Not statistically significant $(\mathrm{p}>0.05)$ 
extraction of LTM has been related with the absence of cortical bone of the canal in CT. CT is recommended when radiographic signs appear in the OPG that show a direct anatomical relationship between the LTM and the canal. However, none of the published studies demonstrate that the preoperative use of CT significantly reduces nerve damage during surgery of LTM.

\section{References}

1. Fuster Torres MA, Gargallo Albiol J, Berini Aytés L, Gay Escoda C. Evaluation of the indication for surgical extraction of third molars according to the oral surgeon and the primary care dentist. Experience in the Master of Oral Surgery and Implantology at Barcelona University Dental School. Med Oral Patol Oral Cir Bucal. 2008;13:E499-504.

2. Rood JP, Shehab BA. The radiological prediction of inferior alveolar nerve injury during third molar surgery. Br J Oral Maxillofac Surg. 1990;28:20-5.

3. Valmaseda-Castellón E, Berini-Aytés L, Gay-Escoda C. Inferior alveolar nerve damage after lower third molar surgical extraction: a prospective study of 1117 surgical extractions. Oral Surg Oral Med Oral Pathol Oral Radiol Endod. 2001;92:377-83.

4. Monaco G, Montevecchi M, Bonetti GA, Gatto MR, Checchi L. Reliability of panoramic radiography in evaluating the topographic relationship between the mandibular canal and impacted third molars. J Am Dent Assoc. 2004;135:312-8.

5. Jhamb A, Dolas RS, Pandilwar PK, Mohanty S. Comparative efficacy of spiral computed tomography and orthopantomography in preoperative detection of relation of inferior alveolar neurovascular bundle to the impacted mandibular third molar. J Oral Maxillofac Surg. 2009;67:58-66.

6. Queral-Godoy E, Valmaseda-Castellón E, Berini-Aytés L, GayEscoda C. Incidence and evolution of inferior alveolar nerve lesions following lower third molar extraction. Oral Surg Oral Med Oral Pathol Oral Radiol Endod. 2005;99:259-64.

7. Blaeser BF, August MA, Donoff RB, Kaban LB, Dodson TB. Panoramic radiographic risk factors for inferior alveolar nerve injury after third molar extraction. J Oral Maxillofac Surg. 2003;61:417-21. 8. Ohman A, Kivijärvi K, Blombäck U, Flygare L. Pre-operative radiographic evaluation of lower third molars with computed tomography. Dentomaxillofac Radiol. 2006;35:30-5.

9. Maegawa H, Sano K, Kitagawa Y, Ogasawara T, Miyauchi K, Sekine J, et al. Preoperative assessment of the relationship between the mandibular third molar and the mandibular canal by axial computed tomography with coronal and sagittal reconstruction. Oral Surg Oral Med Oral Pathol Oral Radiol Endod. 2003;96:639-46.

10. Susarla SM, Dodson TB. Preoperative computed tomography imaging in the management of impacted mandibular third molars. J Oral Maxillofac Surg. 2007;65:83-8.

11. Nakagawa Y, Ishii H, Nomura Y, Watanabe NY, Hoshiba D, Kobayashi K, et al. Third molar position: reliability of panoramic radiography. J Oral Maxillofac Surg. 2007;65:1303-8.

12. Nakamori K, Fujiwara K, Miyazaki A, Tomihara K, Tsuji M, Nakai M, et al. Shimanishi M, Hiratsuka H. Clinical assessment of the relationship between the third molar and the inferior alveolar canal using panoramic images and computed tomography. J Oral Maxillofac Surg. 2008;66:2308-13.

13. Gomes AC, Vasconcelos BC, Silva ED, Caldas Ade F Jr, Pita Neto IC. Sensitivity and specificity of pantomography to predict inferior alveolar nerve damage during extraction of impacted lower third molars. J Oral Maxillofac Surg. 2008;66:256-9.

14. Sedaghatfar M, August MA, Dodson TB. Panoramic radiographic findings as predictors of inferior alveolar nerve exposure following third molar extraction. J Oral Maxillofac Surg. 2005;63:3-7.

15. Tantanapornkul W, Okouchi K, Fujiwara Y, Yamashiro M, Maruoka Y, Ohbayashi N, et al. A comparative study of cone-beam computed tomography and conventional panoramic radiography in as- sessing the topographic relationship between the mandibular canal and impacted third molars. Oral Surg Oral Med Oral Pathol Oral Radiol Endod. 2007;103:253-9.

16. Tantanapornkul W, Okochi K, Bhakdinaronk A, Ohbayashi N, Kurabayashi T. Correlation of darkening of impacted mandibular third molar root on digital panoramic images with cone beam computed tomography findings. Dentomaxillofac Radiol. 2009;38:11-6. 